\title{
CLINICAL EVALUATION OF ROOT CANAL OBTURATION QUALITY USING TWO DIFFERENT SEALERS AND OBTURATION TECHNIQUES BY CONE BEAM COMPUTERIZED TOMOGRAPHY (IN-VIVO STUDY)
}

\author{
Samia M El-Shereif* and Mohamed Ibrahim Rabie**
}

\begin{abstract}
Introduction: new materials and techniques were developed to achieve adequate root canal obturation by complete filling of the canal space with a stable, biocompatible material that prevents the ingress of bacteria and/or its by-products to periapical tissue.

The purpose of this study was to evaluate quality of two different root canal sealer and filling techniques using cone beam computerized tomography (CBCT)

Materials and methods: Seventy-two root canals were prepared using protaper next rotary system. Root canals were divided into two equal groups 36 teeth each. Group I: teeth were obturated using single cone technique with MTA fill apex sealer. Group II: teeth were obturated using continuous wave technique with resin-based sealer (AH plus). The voids within filling materials as well as along dentin walls were examined using CBCT.
\end{abstract}

Result: results revealed that the difference between different thirds was extremely statistically significant in single cone technique, while in continuous wave technique there was no significant difference between thirds. There was no significant difference between both techniques in apical and middle third, while in cervical third there was a significant difference, as single cone showed more voids. Both techniques showed accepted working length of the obturation.

Conclusions: CBCT is an accurate tool for assessment of root canal filling quality. There were more voids present in coronal third in both techniques. Continuous wave technique showed fewer voids in cervical third compared to single cone technique. The present study showed that none of the root canal obturated teeth were gap-free.

KEYWORDS: CBCT, root canal filling, MTA fill apex, AH-plus, continuous wave technique, single cone technique.

* Associate Professor of Endodontics, Faculty of Oral and Dental Medicine, Cairo University.

** Lecturer of Endodontics, College of Dentistry, Suez Canal University. 


\section{INTRODUCTION}

The main goals of successful root canal treatment are to clean the root canal adequately, to remove microorganisms and debris, to shape the canal preserving the original anatomy of the canal and complete filling of the root canal space ${ }^{(1-3)}$.The main causes of endodontic failures are incomplete eradication of the microorganisms and incomplete filling of the root canal spaces ${ }^{(4,5) \text {. }}$

Careful detection of the primary factors that cause the disease and risk factors that negatively affect the tooth post-treatment are the keys of increasing treatment successful rate ${ }^{(6-8)}$. Oral bacteria that present in the saliva can reach to the pulp or periapical lesion through inadequate obturated canals or through defective coronal restoration. So the filling material should provide proof that prevents ingress of bacteria and their byproducts aiming to keep the tooth and the surrounding periapical tissues healthy ${ }^{(9,10)}$. Gutta-percha in combination with root canal sealer has proven to be the material of choice used for root canal filling, sealer is essential to fill the spaces between the dentinal wall and the core interface, and to seal root canal isthmuses, lateral and accessory canals ${ }^{(11-13)}$. Many studies evaluated the adaptability of the root canal filling into the dentin walls. Warm vertical compaction techniques have superior advantages providing dense gutta-percha with superior adaptation to the dentin walls and reproduce the internal root canal morphology ${ }^{(14)}$. Warm vertical compaction techniques was later modified by the use of the System B spreader/plugger (EIE Analytic Technology, Orange, CA), namely "continuous wave technique" (15). However, the extrusion of the filling material beyond the apex is a significant factor to be considered in warm vertical technique ${ }^{(16)}$.

Epoxy resin sealer, AH Plus (Dentsply De Trey, Konstanz, Germany) is a hydrophobic sealer that has been used in association with gutta percha, many studies had demonstrated the capacity of this material to produce an acceptable apical seal ${ }^{(17)}$.
More recently, new filling materials and sealer have been emerged that can lead to more homogenous root canal filling, to achieve the concept of monoblock. Calcium silicate-based materials as mineral trioxide aggregate (MTA)-based root canal sealers have been developed, and these materials have been supposed to be biocompatible, stimulate mineralization, and to provide superior sealing properties. Moreover, these materials have been shown to offer better bond strengths and adaptation to dentin walls that allows adequate filling of the root canal system; including isthmuses, accessory and lateral canals ${ }^{(18,19)}$. MTA Fillapex is an example of MTA based sealers that have the advantages of MTA as release of calcium with high $\mathrm{pH}$ that elicits antibacterial effects and tissue biocompatability. The product is eugenol free and doesn't interfere with bonding materials. ${ }^{(20)}$. Radiographic evaluation of endodontically treated teeth is a very useful technique. It is used to assess a number of factors as root canal morphology, instrumentation and obturation quality, as well as post-operative follow up ${ }^{(21,24)}$. Cone beam computed tomography is helpful non-destructive technique that shows more details, accurate images without superimposition with $3 \mathrm{D}$ view ${ }^{(25-28)}$. Stein advocated that the adequate obturation to be short of the radiographic apex $(0.5-2.0 \mathrm{~mm})^{(29)}$. The purpose of this in-vivo study was to evaluate the quality of root canal filling when comparing single cone and continuous wave technique using two different sealers by $\mathrm{CBCT}$ analysis.

\section{MATERIALS AND METHODS}

\section{Case selection}

The study protocol was reviewed and approved by the Ethics Committee of Institutional Review Board (IRB), Faculty of Dentistry, Umm al Qura University (UQU). Patients above 18 year-old were selected from the outpatient clinics faculty of dentistry in (UQU). With inclusion criteria: closed apex of fully erupted restorable teeth with deep caries or exposed pulp. The patients have non- 
significant systemic disease. Teeth were mixed between single and multiple canals. The exclusion criteria: Patients under 18 year-old, with open apex, non-restorable teeth or third molars.

\section{Radiographic and treatment technique:}

All cases will be exposed preoperative and postoperative treatment to narrow-field CBCT. CBCT were analyzed with I-CAT $120 \mathrm{kVp}, 7 \mathrm{~mA}$ (Imaging Science international LLC, 1910 North Penn Road Hatfield USA). CBCT imaging was analyzed in cross sections in three levels; coronal, middle and apical third.

\section{Cases preparation}

After local anesthesia with Articaine hydrochloride 4\% epinephrine 1:100,000 and proper isolation using rubber dam. The pulp chamber access was performed by a diamond-coated bur (Endo Access Bur); and final flaring was done using endo-Z bur. The working length was assessed by periapical parallel X-rays technique. Glide path and preflaring were performed by manual $\mathrm{k}$-files $(10,15$ and 20 ISO).

All canals were instrumented using ProTaper Next System (Dentsply Maillefer). Copious irrigation with $2.5 \% \mathrm{NaOCl}$ with a 24 -gauge needle (Korea Vaccine Co., Seoul, Korea) was utilized during all the root canal treatment sequence with final flush using 17\% EDTA to remove the smear layer followed by $3 \mathrm{~mL}$ of $2.5 \% \mathrm{NaOCl}$.

After the instrumentation was finished, all canals were dried using paper points (Dentsply Maillefer).

The root canals were then randomly assigned to one of two groups ( $\mathrm{n}=36$ each) for canal obturation using one of the two techniques.

\section{Group I: single cone technique:}

ProTaper gutta-percha matching cone (Dentsply, Sirona) was used as a master cone and coated with MTA Fill-apex sealer then was inserted into the canal till the WL. The excess gutta-percha was cut with a heat carrier and the excess gutta-percha was vertically compacted at the orifice level.

\section{Group II: Continuous wave technique}

A matching GP cone was inserted to the WL and checked for tug-back. AH plus sealer was applied on the canal walls by Lentulo-spiral. A System-B heat source (SybronEndo), at power setting 10 and $200^{\circ} \mathrm{C}$ and fitted with a 0.06 plugger, was used to cut off the GP cone leaving $4 \mathrm{~mm}$ at the apical third. The Calamus system (Dentsply/Tulsa Dental, Johnson City, TN) was used at $180^{\circ} \mathrm{C}$ to backfill the remaining coronal two third of the canal with a 23 -gauge needle. A System B plugger is selected that matches the shape of the prepared root canal and used to condense vertically the thermoplasticized GP.

The access cavities in both groups were sealed with Cavit (ESPE-Premier, Norristown, PA, USA).

\section{Visual analysis by evaluation criteria}

All images were evaluated separately by one endodontist.

A. Voids and gaps.

B. Length of root canal filling.

TABLE (1) Criteria of acceptable length of root canal filling

\begin{tabular}{|l|l|l|}
\hline Variable & Criteria & Definition \\
\hline $\begin{array}{l}\text { Length of root } \\
\text { canal filling }\end{array}$ & Acceptable & $\begin{array}{l}\text { Root filling end 0.5-2 mm } \\
\text { of radiographic apex }\end{array}$ \\
\cline { 2 - 3 } & Overfilled & $\begin{array}{l}\text { Root filling ending at or } \\
\text { beyond the apex }\end{array}$ \\
\cline { 2 - 3 } & Under filled & $\begin{array}{l}\text { Root filling ending } 2 \mathrm{~mm} \\
\text { short of radiographic apex }\end{array}$ \\
\hline
\end{tabular}

\section{Statistical analysis}

Statistical analysis was then performed using a commercially available software program (SPSS 19; SPSS, Chicago, IL, USA).

The frequency of voids and the acceptability of the working length were expressed as number and 
percentages. Chi-square test was used to compare within and between groups. The significance level was set at $\mathrm{p}<0.05$.

\section{RESULTS}

\section{I- Comparison of frequency in different thirds of cross section view of $\mathrm{CBCT}$ within the same group}

\section{a) Single cone technique}

Using single cone techniques, the lowest frequency of voids was noted in the apical third $36.1 \%$ of cases showed no voids, while the remaining cases showed 1 or 2 voids). In comparison, the cervical third showed the highest frequency of voids, with only $11.1 \%$ of cases with no voids and about $28 \%$ of cases showing 3 voids or more). The middle third showed an intermediate frequency with $55.6 \%$ showing 2 voids and $13.9 \%$ with no voids. Chi square test revealed that the difference between different thirds was extremely statistically significant $(\mathrm{P}<0.0001)$, (Table 2, Fig.1)

\section{b) Continuous wave technique}

The lowest frequency of voids was noted in the cervical third (50\% of cases showed no voids, while $41.6 \%$ cases showed 1 or 2 voids). In comparison, the middle third showed the highest frequency of voids, with only $25 \%$ of cases with no voids and $69.4 \%$ of cases showing 1 or 2 voids). The apical third showed an intermediate frequency with 61.1 $\%$ showing 1 or 2 voids and $27.8 \%$ with no voids. Chi square test revealed that the difference between different thirds was not statistically significant $(\mathrm{P}=0.43)$, (Table 3, Fig.2)

TABLE (2): Frequency of voids in different thirds of cross section view of CBCT in single cone technique.

\begin{tabular}{|c|c|c|c|c|c|c|c|c|}
\hline & \multicolumn{2}{|c|}{ Apical third } & \multicolumn{2}{|c|}{ Middle third } & \multicolumn{2}{|c|}{ Cervical third } & \multirow{2}{*}{$\mathrm{X}^{2}$} & \multirow{2}{*}{$\mathrm{P}$} \\
\hline & No. & Percent & No. & Percent & No. & Percent & & \\
\hline 0 Void & 13 & 36.1 & 5 & 13.9 & 4 & 11.1 & \multirow{6}{*}{26.44} & \multirow{6}{*}{$<0.0001^{*}$} \\
\hline 1 Void & 15 & 41.7 & 7 & 19.4 & 8 & 22.2 & & \\
\hline 2 Voids & 8 & 22.2 & 20 & 55.6 & 14 & 38.9 & & \\
\hline 3 Voids & 0 & 0 & 2 & 5.6 & 5 & 13.9 & & \\
\hline 4 Voids or more & 0 & 0 & 2 & 5.6 & 5 & 13.9 & & \\
\hline Total & 36 & 100 & 36 & 100 & 36 & 100 & & \\
\hline
\end{tabular}

Significance level P<0.05, *significant

TABLE (3): Frequency of voids in different thirds of cross section view of CBCT in Continuous wave technique.

\begin{tabular}{|c|c|c|c|c|c|c|c|c|}
\hline & \multicolumn{2}{|c|}{ Apical third } & \multicolumn{2}{|c|}{ Middle third } & \multicolumn{2}{|c|}{ Cervical third } & \multirow[t]{2}{*}{$X^{2}$} & \multirow[t]{2}{*}{$\mathrm{P}$} \\
\hline & No. & Percent & No. & Percent & No. & Percent & & \\
\hline 0 Void & 10 & 27.8 & 9 & 25 & 18 & 50 & \multirow[t]{6}{*}{7.97} & \multirow[t]{6}{*}{$0.43 \mathrm{~ns}$} \\
\hline 1 Void & 15 & 41.7 & 15 & 41.6 & 11 & 30.6 & & \\
\hline 2 Voids & 7 & 19.4 & 10 & 27.8 & 4 & 11.1 & & \\
\hline 3 Voids & 4 & 11.1 & 2 & 5.6 & 3 & 8.3 & & \\
\hline 4 Voids or more & 0 & 0 & 0 & 0 & 0 & 0 & & \\
\hline Total & 36 & 100 & 36 & 100 & 36 & 100 & & \\
\hline
\end{tabular}




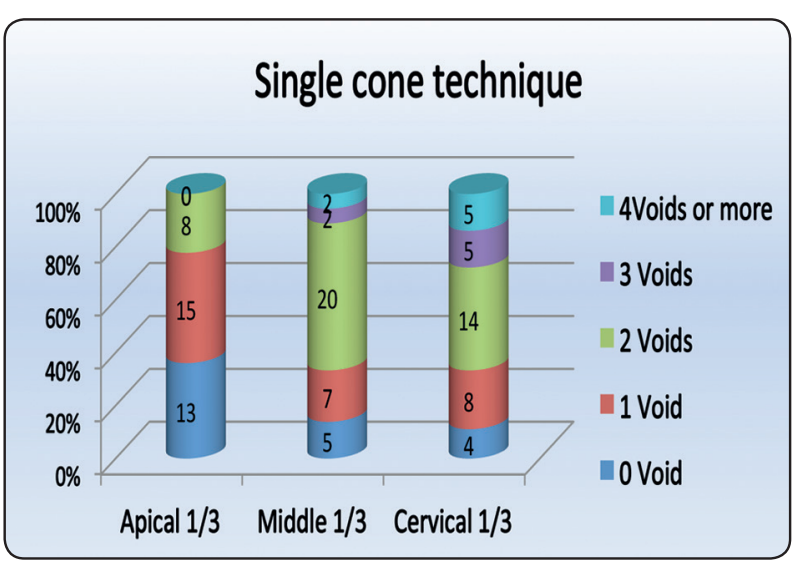

Fig (1): Column chart showing frequency of voids in different thirds of cross section view of CBCT in single cone technique.

\section{II- Comparison of both techniques}

In the apical $1 / 3$, the percentage of cases having no voids was $36.1 \%$ in single cone technique in comparison to $27.8 \%$ in Continuous wave technique. Moreover, 4 cases in Continuous wave technique showed 3 voids, while the maximum number of voids in single cone technique was 2 voids only. However, chi square test revealed that this difference was not statistically significant ( $\mathrm{p}=0.348)$, (Table 4, Fig.3)

In the middle $1 / 3$, the percentage of cases having no voids was $13.9 \%$ in single cone technique in comparison to $25 \%$ in Continuous wave technique.

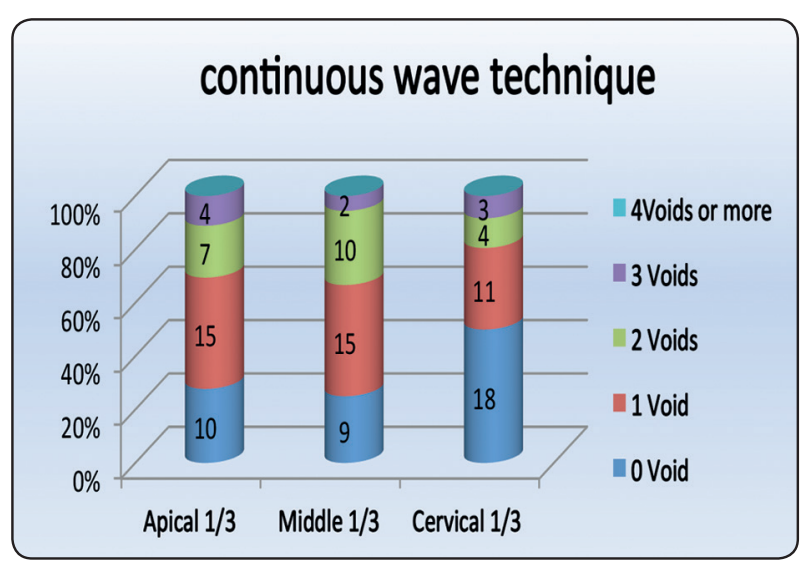

Fig (2): Column chart showing frequency of voids in different thirds of cross section view of CBCT in Continuous wave technique.

Moreover, no cases in Continuous wave technique showed 4 voids or more, in comparison to $5.6 \%$ in single cone technique. However, chi square test revealed that this difference was not quite statistically significant ( $\mathrm{p}=0.052)$, (Table 4, Fig.3)

In the cervical $1 / 3$, the percentage of cases having no voids was $50 \%$ in Continuous wave technique in comparison to $11.1 \%$ in single cone technique. Moreover, $11.1 \%$ of cases in Continuous wave technique showed 2 voids, in comparison to $38.9 \%$ in single cone technique. Chi square test revealed that this difference was highly statistically significant ( $\mathrm{p}=0.0004)$, (Table 4, Fig.3)

TABLE (4): Comparison between both techniques regarding the frequency of voids in different thirds of axial section view of $\mathrm{CBCT}$

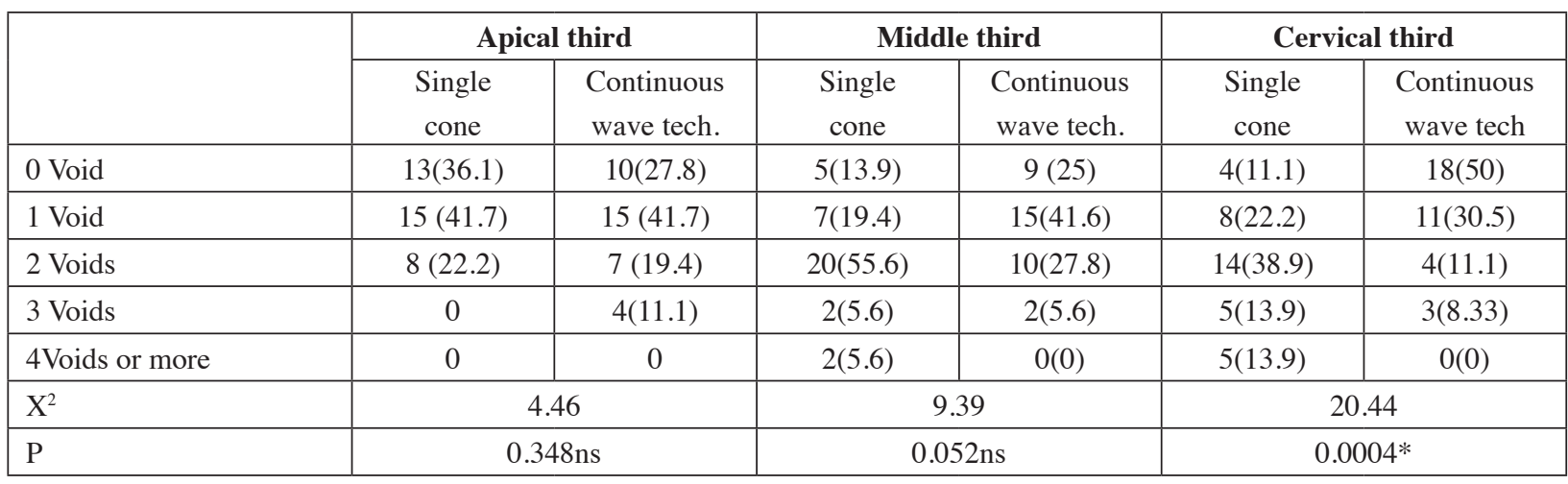

Significance level $P<0.05$, 


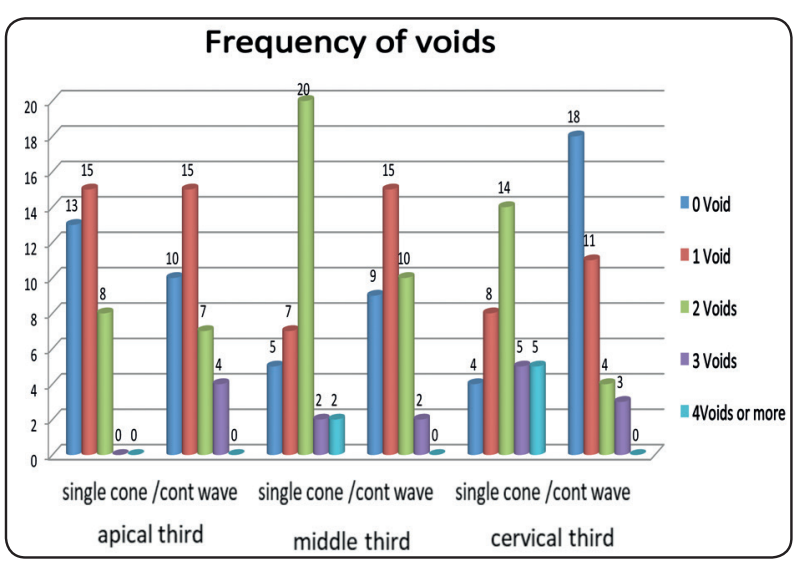

Fig (3): Column chart showing frequency of voids in different thirds of cross section view of CBCT in single cone and Continuous wave technique.

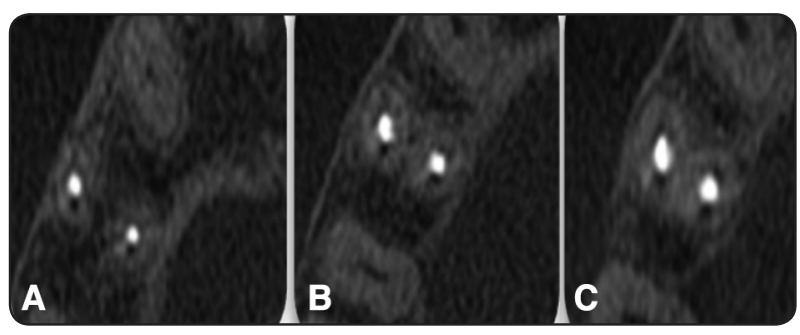

Fig. (4) Single cone technique: axial view of CBCT show (A) apical, (B) middle and(C) cervical thirds.
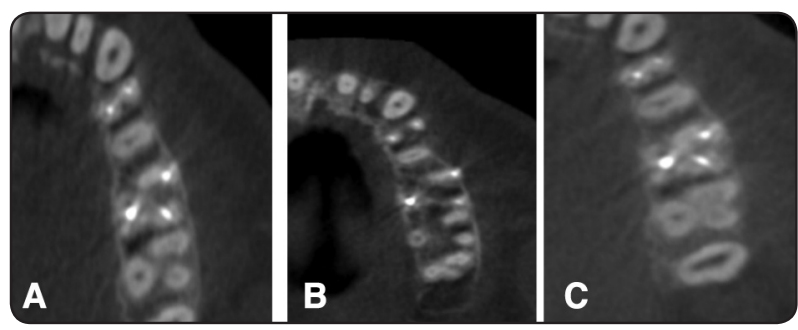

Fig. (5) Continuous wave technique axial view of CBCT. show (A) apical, (B) middle and(C) cervical thirds.

\section{III-Comparison of evaluation working length be- tween single cone and single continuous wave technique using CBCT}

The percentage of cases showing acceptable working length was $91.7 \%$ in single cone technique, in comparison to $88.9 \%$ in continuous wave technique. Moreover, $8.3 \%$ of cases in continuous wave technique showed under-filling, in comparison to $5.5 \%$ in single cone. Both techniques showed a single case of over filling. Chi square test revealed that this difference was not statistically significant $(\mathrm{p}=0.55)$, (Table 5, Fig. 6).

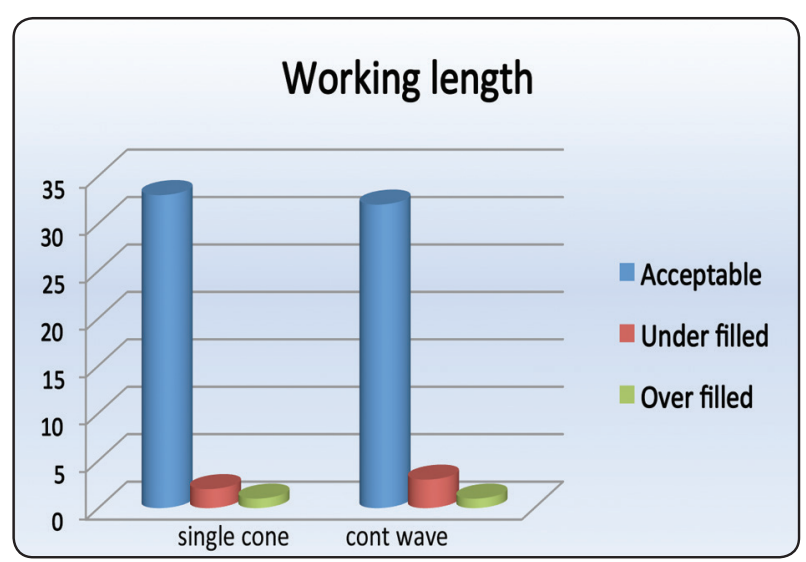

Fig. (6): Column chart showing frequency of acceptance of working lengths of CBCT in single cone and continuous wave technique.

TABLE (5) Comparison between both techniques regarding evaluation of working using CBCT

\begin{tabular}{|c|c|c|c|c|c|c|}
\hline \multirow{2}{*}{} & \multicolumn{2}{|c|}{ Single cone technique } & \multicolumn{2}{|c|}{ Continuous wave technique } & \multirow{2}{*}{$\mathrm{X}^{2}$} & \multirow{2}{*}{$\mathrm{P}$} \\
\cline { 2 - 5 } & No. & $\%$ & No. & $\%$ & & \\
\hline Acceptable & 33 & 91.7 & 32 & 88.9 & & \multirow{2}{*}{$0.55 \mathrm{~ns}$} \\
\hline Under filled & 2 & 5.5 & 3 & 8.3 & \\
\hline Over filled & 1 & 2.8 & 1 & 2.8 & & \\
\hline Total & 36 & 100 & 36 & 100 & & \\
\hline
\end{tabular}

Significance level $P<0.05$, ns=non-significant 


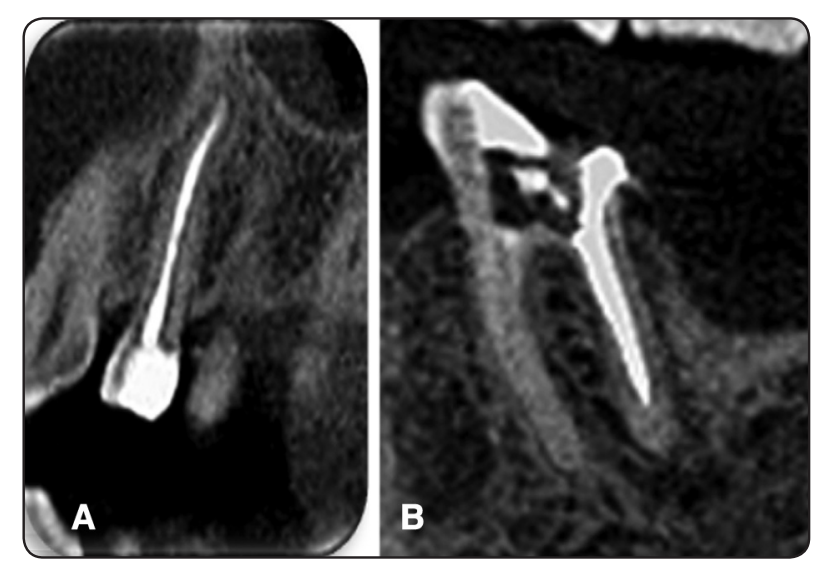

Fig (7) CBCT showing working lengths of a. Single cone tech b. CW technique.

\section{DISCUSSION}

A high-quality root canal filing without voids or gaps is a main prerequisite to have successful root canal therapy and is a major factor for preventing leakage with subsequent periapical disease. Many researchers reported that gutta-percha has varying degree of microleakage, therefore new filling materials, sealers and techniques were developed ${ }^{(1,13,16,18)}$.

Clinical evaluation of root canal fillings is limited to the use of radiographs, usually in two dimensions; in this study CBCT was used to produce 3diminsional clear image and overcome radiograph limitations. Zaslansky et al. ${ }^{(24)}$ reported that CBCT analysis has been approved as a qualitative and quantitative method to assess the presence of voids through root canal filling. This study was carried out to evaluate clinically the technical quality of root canal treatment performed on adult patients attending the Faculty of Dentistry, University of Umm Alqura. A few studies ${ }^{(30)}$ have used (in vivo) human teeth to evaluate the amount of voids in root canal fillings by CBCT, the present study was conducted on patient with variable teeth with the complex canal morphology to have more reliable results when measuring the percentage of void, Most previous studies that have evaluated filling quality used artificial teeth with a single canal and with few anatomical variations, these samples might not have anatomical structures that are present in human teeth, and don't reflect the complex root canal morphology encountered in clinical situations ${ }^{(31-32)}$. In the present study one operator did all the endodontic procedures to decrease the human variability ${ }^{(12,13)}$.

GP is widely used solid core material for root canal filling; sealer is used to fill minor gaps between GP and dentin walls and to form fluid tight seal. However, these sealers might cause some degree of microleakage, so it should be used in minimal amount. ${ }^{(33,34)}$ to achieve this goal master GP cone should closely fit the diameter of the last apical file used reaching the full working length. Capar et al. . $^{(35)}$ concluded that the matched cone of ProTaper Next is suitable with its file. Therefore; this study was conducting using rotary ProTaper nickel-titanium files, Protaper single GP matching cone and MTA sealer in order to produce the proper fitness of the canal $^{(36)}$. The composition of MTAFillapex rendering it more stable and biocompatible and is supposed to lead to a tertiary monoblock. ${ }^{(20,33,34,37,38)}$. Zhang et al. ${ }^{(13)}$ reported that in a single-cone technique, the volume of sealers is more than the volume of gutta-percha cone, such that ratio might lead to the formation of voids (gap) and decreases the quality of the root canal filling. Continuous wave technique provided superior root canal filling and capable of pushing thermoplasticized gutta-percha into lateral canals and isthmuses ${ }^{(14-16)}$. In present study, results revealed that filling showed less voids at apical and middle thirds in both techniques without significant difference, this could be attributed to the harmony of master apical file and matching GP cone that might decrease the number of voids and produce better adaptation. While more number of voids was detected in the coronal third than in the apical third in both groups. Our results were in agreement with Iglecias et al. ${ }^{(15)}$ and Alshehri et al ${ }^{(39)}$ who measured the volume of voids in the apical one-third of human 
mandibular first molars using micro-CT, and found no significant difference between the SC and $\mathrm{CW}$ groups. Considering the limits of our study, we can affirm that continuous wave technique seal the canal in coronal third better than single cone technique that showed greater number of voids (table 3, fig 4 and 5). Our results were contradicting to the results reported by Kim et al. ${ }^{(34)}$ who concluded that continuous wave technique showed more voids in coronal third in comparison to single cone technique. Obeidat and Abdallah (36), and Gandolfi ${ }^{(40)}$. Mckissock et al. ${ }^{(41)}$ studied in vitro the leakage test to compare the sealing ability of continuous wave of condensation technique and the sealing ability of single cone technique. He concluded that, single-cone filling technique showed statistically significant higher leakage than a continuous weave of condensation, this could be attributed to the more coronal voids in single cone technique. Inan et al. ${ }^{(31)}$ concluded that the apical sealing of the single-cone technique is comparable to the Thermafil and lateral condensation techniques.

Confining the filling materials to the root canal space resulted in a higher success rate ${ }^{(29,42)}$. Swartz et al. ${ }^{(43)}$ reported a higher success rate when the root canal obturation ended close to, or at the radiographic apex. In the present study the working length in relation to radiographic apex as shown in (table 5, fig 6 and 7) were mostly accepted. Chi square test revealed that the difference between both groups was not statistically significant.

\section{CONCLUSIONS}

Within the limitation of the present study single matched cone technique has a good density in the apical one-third as that of continuous wave technique, so it could be used for obturation of narrow canals. Single cone showed inferior density in the coronal third of the root canal that might lead to leakage, so it could be improved by adding accessory cones Gutta-percha in wide canal. Both techniques showed acceptable filling length. Single cone technique is simple and save more time. In this study, the overall quality of root canal treatment as assessed by the given criteria was shown to be accepted.

\section{REFERENCES}

1. Ørstavik D. Materials used for root canal obturation: technical, biological and clinical testing. Endod Topics 2005;12: 25-38.

2. Loest, C. Quality guidelines for endodontic treatment: consensus report of the European Society of Endodontology. International Endodontic Journal. 2006; 39(12), 921-930.

3. F. M. Burke, C. D. Lynch, R. N'1 R'Iord' Ain, and A. Hannigan, "Technical quality of root canal fillings performed in a dental school and the associated retention of root-filled teeth: a clinical follow-up study over a 5-year period," Journal of Oral Rehabilitation. 2009; (36), no. 7 , pp. 508-515.

4. Siqueira JF., Jr Aetiology of root canal treatment failure: Why well-treated teeth can fail. Int Endod J.2001;34:1-10

5. Estrela C, Guedes AO, Silva JA, Leles CR, Estrela CRA, Pécora JD. Diagnostic and clinical factors associated with pulpal and periapical pain. Braz Dent J 2011;22:306-311.

6. Caldwell DE, Atuku E, Wilkie DC, Wivcharuk KP, Karthikeyan S, Korber DR, et al. Germ theory vs. community theory in understanding and controlling the proliferation of biofilms. Adv Dent Res. 1997;11:4-13

7. Beveridge TJ. Structures of gram-negative cell walls and their derived membrane vesicles. Bacteriol J. 1999; 181:4725-33

8. Y.-L.Ng, V.Mann, and K. Gulabivala, Tooth survival following non-surgical root canal treatment: a systematic review of the literature, International Endodontic Journal, $2010 ; 43,3,171-189$,

9. Torabinejad M, Ung B, Kettering J. In vitro bacterial penetration of coronally unsealed endodontically treated teeth. J Endod. 1990;16:566-9.

10. Nair PNR, Sjögren U, Figdor D, Sundqvist G. Persistent periapical radiolucencies of root filled human teeth, failed endodontic treatments and periapical scars. Oral Surg Oral Med Oral Pathol 1999;87:617-627.

11. Wu, M.K., Fan, B., Wesselink, P.R.: Diminished leakage 
along root canals filled with gutta percha without sealer over time: a laboratory study. Int. Endod. J. 2000; 33, $121-125$.

12. Collins J, Walker MP, Kulild J, Lee C. A comparison of three gutta-percha obturation techniques to replicate canal irregularities. J Endod 2006;32:762-5.

13. Zhang W, Peng B and Li Z. Assessment of a new root canal sealer's apical sealing ability Oral Surg. Oral Med. Oral Pathol. Oral Radio. Endod. 2009; 107 79-82.

14. Buchanan LS. The continuous wave of obturation technique: 'centered' condensation of warm Gutta-percha in 12 seconds. Dent Today 1996;15:60-2,64.

15. Iglecias, E.F.; Freire, L.G.; de Miranda Candeiro, G.T.; Dos Santos, M.; Antoniazzi, J.H.; Gavini, G. Presence of voids after continuous wave of condensation and singlecone obturation in mandibular molars: A micro-computed tomography analysis. J. Endod. 2017, 43, 638-642.

16. Budd CS, Weller RN, Kulild JC. A comparison of thermoplasticized injectable gutta-percha obturation techniques. J Endod 1991;17:260-4.

17. Bouillaguet S, Shaw L, Barthelemy J, Krejci I, Wataha JC. Long term ability of pulp canal sealer, AH-Plus, GuttaFlow and Epiphany. International Endodontic Journal. 2008; 41, 219-26.

18. Gandolfi MG, Iacono F, Agee $\mathrm{K}$ et al. Setting time and expansion in different soaking media of experimental accelerated calcium-silicate cements and ProRoot MTA. Oral Surgery, Oral Medicine, Oral Pathology, Oral Radiology, Endodontics. (2009b); 108, e39-45.

19. Gandolfi MG, Prati C. MTA and F-doped MTA cements used as sealers with warm gutta-percha. Long-term study of sealing ability. International Endodontic Journal. 2010; 43, 889-901.

20. Min, K.S. Clinical use of a premixed MTA-based root canal sealer. J. Korean Soc. Dent. Mater. 2016, 43, 4-5.Int. Endod. J. 2000, 33, 340-345.

21. H€ubscher W, Barbakow F, Peters OA. Root-canal preparation with FlexMaster: canal shapes analysed by micro-computed tomography. International Endodontic Journal. 2003. 36, 740-7.

22. Sunay H, Tanalp J, Dikbas I, Bayirli G. Cross-sectional evaluation of the periapical status and quality of root canal treatment in a selected population of urban Turkish adults. Int Endod J 2007;40:139-45.
23. Low KM, Dula K, Bürgin W, von Arx T. Comparison of periapical radiography and limited cone-beam tomography in posterior maxillary teeth referred for apical surgery. $\mathrm{J}$ Endod. 2008;34: 557-562.

24. Zaslansky, P., Fratzl, P., Rack, A., Wu, M.-K., Wesselink, P.R., Shemesh, H.: Identification of root filling interfaces by microscopy and tomography methods. Int. Endod. J. 2011;44, 395-401

25. Cotton TP, Geisler TM, Holden DT, Schwartz SA, Schindler WG. Endodontic applications of cone-beam volumetric tomography. J Endod. 2007; 33(9):1121-32.

26. Scarfe WC, Farman AG. What is cone beam CT and how does it work? Dent Clin N Amer 2008;52:707-30

27. Strateman SA, Huang JC, Maki K, Miller AJ, Hatcher DC. Comparison of cone beam computed tomography imaging with physical measures. Dentomaxillofac Rad 2008;37:8093.

28. Randy L Ball, Joao V Baebizam, Nestor Cohencan. Intraoperative endodontic application of cone beam computed tomography. J Endod. 2013;39: 548-557.

29. Stein T. Radiographic "Working length" revisited. Oral Surg Oral Med Oral Path 1992;74:796-9.

30. Song D, Zhang L, Zhou W, Zheng Q, Duan X, Zhou $\mathrm{X}$, and Huang D. Comparing cone-beam computed tomography with periapical radiography for assessing root canal obturation in vivo using microsurgical findings as validation. Dentomaxillofac Radiol. 2017; 46(5): 20160463.

31. Inan U, Aydin C, Tunca YM, Basak F. In vitro evaluation of matched-taper single-cone obturation with a fluid filtration method. J Can Dent Assoc. 2009 Mar;75(2):123-123c.

32. El Sayed, M.A.; Taleb, A.A.; Balbahaith, M.S. Sealing ability of three single-cone obturation systems: An in vitro glucose leakage study. J. Conserv. Dent. 2013, 16, 489-493.

33. Jho, W.; Park, J.W.; Kim, E.; Song, M.; Seo, D.G.; Yang, D.K.; Shin, S.J. Comparison of root canal filling quality by mineral trioxide aggregate and gutta percha cones/AH plus sealer. Dent. Mater. J. 2016, 35, 644-650.

34. Kim S, Kim S, Park GW, Jung Y and Shin SJ. Comparison of the Percentage of Voids in the Canal Filling of Calcium Silicate-Based Sealer and Gutta Percha Cones Using Two Obturation Techniques. Materials 2017, 10, 1170 
35. Capar I D, Ertas H, Ok E and Arslan H. Comparison of single cone obturation performance of different novel nickel-titanium rotary systems. Acta Odontologica Scandinavica. 2014; 72: 537-542.

36. Obeidat R S, Abdallah H. Radiographic evaluation of the quality of root canal obturation of single-matched cone Gutta-percha root canal filling versus hot lateral technique. Saudi Endodontic Journal. 2014; 4: 58-63.

37. Jung, M., Lommel, D., Klimek, J.: The imaging of root canal obturation using micro-CT. Int Endod J. 2005; 38, $617-626$.

38. EL-Ma'aita AM, Qualtrough AJE, Watts DC. A microcomputed tomography evaluation of mineral trioxide aggregate root canal fillings. Journal of Endodontics 2012; $38,670-2$.

39. Alshehri, M.; Alamri, H.M.; Alshwaimi, E.; Kujan, O. Micro-computed tomographic assessment of quality of obturation in the apical third with continuous wave vertical compaction and single match taper sized cone obturation techniques. Scanning 2016, 38, 352-356, doi:10.1002/ sca. 21277 .

40. Gandolfi M. G., Parrilli A. P., FiniM, Prati1C and Dummer PMH. 3D micro-CT analysis of the interface voids associated with Thermafil root fillings used with AH Plus or a flowable MTA sealer International Endodontic Journal. 2003 46, 253-263.

41. McKissock AJ, Mines P, Sweet MB, Klyn SL. Ten-month in vitro leakage study of a single-cone obturation system. US Army Med Dep J 2011;Jan-Mar:42-7.

42. KojimaK,InamotoK, Nagamatsu K. Success rate of endodontic treatment of teeth with vital and nonvital pulps. A meta-analysis. Oral Surg Oral Med Oral Pathol Oral Radiol Endod 2004;97:95-9.

43. Swartz D, Skidmore A, Griffin J. Twenty years of endodontic success and failure. J Endod 1983;9:198-202. 